\title{
Comparison of Spasticity in Spinal Cord Injury and Stroke Patients Using Reflex Period in Pendulum Test
}

\author{
Kristjana Kristinsdottir (2), Gigja Magnusdottir (1), Belinda Chenery (2), Vilborg \\ Gudmundsdottir (1), Halla Kristin Gudfinnsdottir (2), Halldor Karason (2), Gudbjorg K \\ Ludvigsdottir (1), Thordur Helgason $(1,2)$
}

(1) Rehabilitation Department at Grensas, Landspitali-University Hospital, Reykjavík, Iceland; (2) Health Technology Center, Reykjavik University - Landspitali-University Hospital, Reykjavik, Iceland.

This article is distributed under the terms of the Creative Commons Attribution Noncommercial License (CC BY-NC 4.0) which permits any noncommercial use, distribution, and reproduction in any medium, provided the original author(s) and source are credited.

\begin{abstract}
Spasticity is a motor impairment present in patients with both stroke and spinal cord injury. In this research, the results from the Wartenberg pendulum test, performed on stroke and spinal cord injury patients using goniometers and electromyogram recordings of the quadriceps, were reviewed and a new parameter to quantify spasticity was extracted. The Reflex Period (RP) of the pendulum test was defined as the time span from $50 \%$ of the maximum velocity of the leg swing to the activation of muscle contraction in the quadriceps, determined from the EMG. The results suggest that the reflex period in stroke patients is generally shorter than in those suffering from spinal cord injury.
\end{abstract}

Key Words: Spasticity, Wartenberg pendulum test, Stroke, Spinal Cord Injury.

Eur J Transl Myol 30 (1): 154-158, 2020

Spasticity is a motor impairment present in patients with various neurological disorders including stroke and spinal cord injury. It is characterized by the hypersensitivity of the stretch reflexes but its complete mechanisms are poorly understood. ${ }^{1}$ Spasticity affects the mobility and therefore quality of life of those living with it. A precise method to quantify spasticity is thus fundamental for early intervention and correct treatment to optimize recovery outcomes. In 1980, Lance proposed a definition of spasticity that, to this day, has been the most prominent one. Lance's definition states that spasticity is a motor disorder characterized by a velocitydependent increase in tonic stretch reflexes with exaggerated tendon jerks, resulting from hyperexcitability of the stretch reflex, as one component of the upper motorneuron syndrome. ${ }^{2}$ Disturbance anywhere along the pyramidal tract or extrapyramidal fibers, leading to a lack of inhibition in lower motorneurons, is the cause of spasticity. ${ }^{3}$ Spasticity occurs due to damage of myelin and axonal fibers along with deterioration of the upper neuron stretch reflex. Mechanism that contribute to the development of spasticity include changes of afferent input coming to spinal motor neurons, the changes in reflex arcs that affect motor neurons' excitability and the changes of motor neurons' internal features. ${ }^{4}$ Spasticity does not only consist of neurogenic resistance but may also involve complex changes in muscular systems leading to non-neurogenic resistance. These changes may include alterations in muscle fiber size and length along with modifications in fiber type distributions. Changes in mechanical and morphological properties of intra- and extracellular materials may also contribute to spasticity. ${ }^{5-}$ ${ }^{8}$ Consequently, it is logical that spasticity assessment consists of both electrophysiological and biomechanical factors. The Wartenberg test was introduced in the 1950s as a method of assessing spasticity in the clinical setting, ${ }^{9}$ and has proven to be sensitive to the presence and severity of spasticity. ${ }^{10-11}$ The Wartenberg test (i.e., the pendulum test) is based on letting the lower leg swing freely under the influence of gravity while recording joint kinematics. The pendulum test is most commonly used to quantify extensor spasticity but the presence of flexor spasticity does not affect the results. ${ }^{12}$ In 1984 Bajd and Vodovnik derived the relaxation indexes (R1 and R2) from the test. ${ }^{13}$ Since then, various parameters such as the maximum velocity and acceleration, ${ }^{10,14}$ area under the pendulum curve, ${ }^{15}$ and frequency, ${ }^{14}$ have been derived. Overall, White et al extracted 13 parameters from the Wartenberg test performed on children with $\mathrm{CP}$ as well as able-bodied children using 3D analysis. They concluded that the pendulum test is a measure of an active component of spasticity (reflex), chronic changes 


\section{High density EEG to assess TMS treatment in schizophrenia}

Eur J Transl Myol 30 (1): 154-159, 2020

in musculotendinous tissue, and the 'rest state' of muscle tone. ${ }^{14}$ In the presented work, the difference in spasticity between a group of spinal cord injury patients and a group of stroke patients will be examined using the Wartenberg pendulum test and a simultaneous EMG recording. A new parameter, the reflex period, was extracted from the test results. The reflex period was defined as the time period from $50 \%$ of the maximum velocity of the leg to the first EMG signal indicating muscle contraction.

\section{Materials and Methods}

Data from two separate studies, one on spinal cord injury patients, ${ }^{16}$ and the other on stroke patients were analyzed. Both studies were focused on transcutaneous Spinal Cord Stimulation (tSCS) but a Wartenberg test with goniometers on the knee joint was performed and electromyography (EMG) of the quadricpes was recorded simultaneously. The study on stroke patients used four phases (A1, B1, A2, B2) of alternating baseline (A) and intervention (B) An 18 to 24 weeks washout period was arranged in between the first set of phases (A1 and B1) and the second set of phases (A2 and B2). Included in each phase were three sessions of measurements performed on separate days but at the same time of the day. Measurements were performed at the Medical Technology Centre of Landspitali University Hospital and Reykjavik University. The study on spinal cord injury patients consisted of three assessment sessions, one before stimulation, the next one immediately after and the last one 2 hours after stimulation. Three repetitions of the Wartenberg pendulum test were included in each assessment session. Measurements were performed at the rehabilitation department at Grensas, Landspitali University Hospital. ${ }^{16}$ In both studies, the Wartenberg test was performed by a physical therapist who dropped the lower leg from a horizontal position while the patient was seated. Joint kinematics were recorded as the leg oscillated freely under the influence of gravity. In a healthy individual, the lower leg acts as a damped pendulum but as spasticity increases the first swing excursion reduces, the mean number of number and duration of oscillations decreases and the final resting angle becomes smaller. ${ }^{10}$ In the study on stroke patients, electro-goniometers were used to evaluate the oscillatory patterns of the swinging leg. All EMG and goniometer recordings were performed using an eego mylab device (ANT Neuro, Enschede,
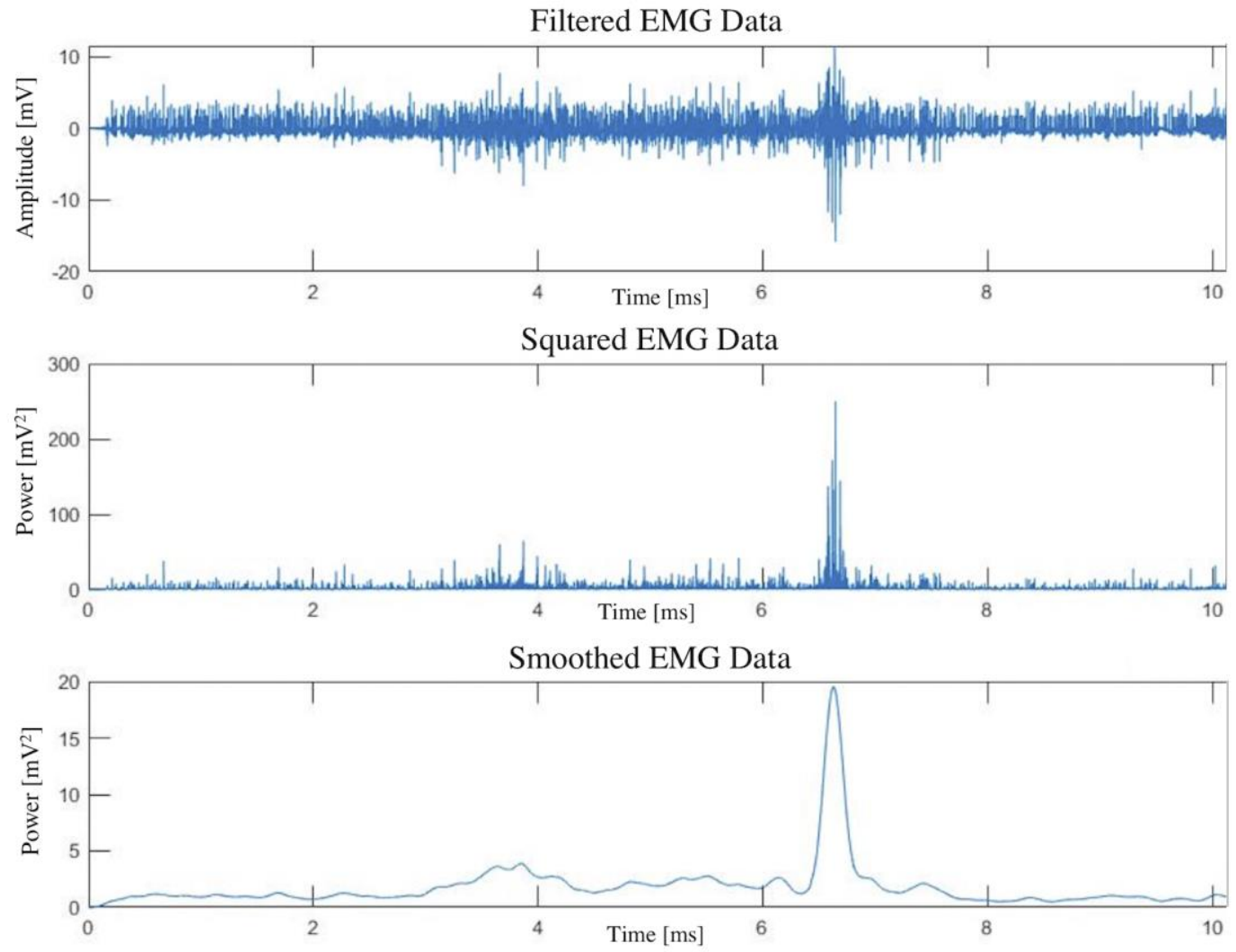

Fig 1. The processing stages of the EMG data. The raw data was filtered with the lower cutoff frequency at $10 \mathrm{~Hz}$ and the higher cutoff frequency at $500 \mathrm{~Hz}$ along with notch filters at $50 \mathrm{~Hz}, 100 \mathrm{~Hz}, 150 \mathrm{~Hz}$ and so forth. The data was then squared and smoothed with a Gaussian filter. 
Table 1.The results on spinal cord injury patients

\begin{tabular}{|c|c|c|c|c|}
\hline \multicolumn{2}{|r|}{ [ms] } & $\mathrm{r} 1$ & $\mathrm{r} 2$ & r3 \\
\hline \multirow{3}{*}{ 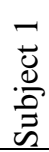 } & stage 1 & 378 & 550 & 416 \\
\hline & stage 2 & 383 & 342 & 154 \\
\hline & stage 3 & 288 & 774 & 233 \\
\hline \multirow{3}{*}{ 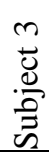 } & stage 1 & 386 & 403 & 419 \\
\hline & stage 2 & 231 & 162 & 183 \\
\hline & stage 3 & 396 & 265 & 431 \\
\hline \multirow{3}{*}{ 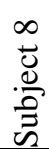 } & stage 1 & 470 & 404 & 346 \\
\hline & stage 2 & 411 & 379 & 397 \\
\hline & stage 3 & 547 & 359 & 344 \\
\hline \multirow{3}{*}{$\begin{array}{l}a \\
\frac{\tilde{U}}{0} \\
\frac{\tilde{U}}{0} \\
\tilde{n}\end{array}$} & stage 1 & 383 & 402 & 376 \\
\hline & stage 2 & 432 & 340 & 413 \\
\hline & stage 3 & $N A$ & 316 & 306 \\
\hline
\end{tabular}

Netherlands) at a sampling rate of $1024 \mathrm{~Hz}$. In the study on stroke patients, ${ }^{16}$ EMG data were acquired using a wireless KINE System (KINE ehf., Iceland) at $1.6 \mathrm{kS} / \mathrm{s}$ per channel. From the Wartenberg pendulum test, knee movements were measured with goniometers. The EMG data were processed with Matlab R2014b (The MathWorks, Inc.) using the open-source toolbox EEGLab. A 4th order Butterworth high-pass filter with cutoff frequency at $10 \mathrm{~Hz}$ and a low-pass filter at $500 \mathrm{~Hz}$ was applied along with notch filters at $50 \mathrm{~Hz}, 100 \mathrm{~Hz}$, $150 \mathrm{~Hz}$ and so forth. The data was smoothed with a Gaussian filter prior to the analysis and the EMG data was squared in order to clarify the results. The processing stages of the EMG data can be seen in Figure 1. The reflex period (RP) was defined as the time span from $50 \%$ of the maximum velocity of the leg swing to the activation of muscle contraction in the quadriceps, determined from the EMG

\section{Results and Discussion}

The results obtained from the study on spinal cord injury patients $^{16}$ can be seen in Table 1 . The results are presented in milliseconds ( $\mathrm{ms}$ ). The average RP is 370.28 ms with a standard deviation of $72.10 \mathrm{~ms}$. The results from the study on stroke patients can be seen in Table 2 . The results are presented in milliseconds (ms). The average RP is $214.56 \mathrm{~ms}$ with a standard deviation of $53.85 \mathrm{~ms}$. The results of both groups are graphically compared in Figure 2. The box plots depict the mean and the standard deviation is represented with the error bars. The results suggest that the reflex period in stroke patients is generally shorter than in those suffering from spinal cord injury. This indicates that the brain might accelerate the stretch reflex. The RP reflects the time that passes during the stretch reflex pathway. The stretch reflex pathway begins when a muscle lengthens so the muscle spindle is stretched. The sensory impulse from

\begin{tabular}{|c|c|c|c|c|c|}
\hline & & {$[\mathrm{ms}]$} & $\mathrm{r} 1$ & $\mathrm{r} 2$ & $\mathrm{r} 3$ \\
\hline \multirow{12}{*}{ 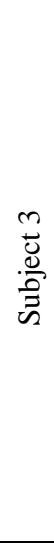 } & \multirow{3}{*}{ Z } & day 1 & 174 & 153 & 114 \\
\hline & & day 2 & 132 & 83 & 142 \\
\hline & & day 3 & 213 & 254 & 202 \\
\hline & \multirow{3}{*}{$\bar{n}$} & day 1 & 165 & 45 & 267 \\
\hline & & day 2 & 255 & 87 & 48 \\
\hline & & day 3 & 160 & 158 & 194 \\
\hline & \multirow{3}{*}{2} & day 1 & $N A$ & $N A$ & $N A$ \\
\hline & & day 2 & 149 & 176 & 108 \\
\hline & & day 3 & 60 & 73 & 60 \\
\hline & \multirow{3}{*}{ ๓ี } & day 1 & 125 & 155 & 149 \\
\hline & & day 2 & 224 & 187 & 209 \\
\hline & & day 3 & $N A$ & $N A$ & $N A$ \\
\hline \multirow{12}{*}{ 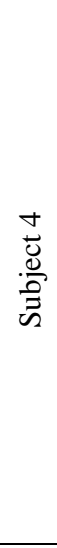 } & \multirow{3}{*}{ Z } & day 1 & 232 & 288 & 270 \\
\hline & & day 2 & 222 & 243 & 271 \\
\hline & & day 3 & 268 & 251 & 240 \\
\hline & \multirow{3}{*}{$\bar{n}$} & day 1 & 240 & 225 & 164 \\
\hline & & day 2 & 251 & 244 & 243 \\
\hline & & day 3 & 252 & 339 & 346 \\
\hline & \multirow{3}{*}{2} & day 1 & $N A$ & $N A$ & $N A$ \\
\hline & & day 2 & 240 & 180 & 249 \\
\hline & & day 3 & 235 & 256 & 286 \\
\hline & \multirow{3}{*}{ 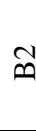 } & day 1 & $N A$ & $N A$ & $N A$ \\
\hline & & day 2 & 270 & 299 & 319 \\
\hline & & day 3 & 270 & 279 & 291 \\
\hline \multirow{12}{*}{$\begin{array}{l}n \\
\frac{n}{0} \\
\frac{0}{0} \\
0 \\
0\end{array}$} & \multirow{3}{*}{ Z } & day 1 & $N A$ & $N A$ & $N A$ \\
\hline & & day 2 & 218 & 216 & 234 \\
\hline & & day 3 & 239 & 206 & 202 \\
\hline & \multirow{3}{*}{$\bar{n}$} & day 1 & 256 & 252 & 238 \\
\hline & & day 2 & 225 & 234 & 243 \\
\hline & & day 3 & 243 & 263 & 270 \\
\hline & \multirow{3}{*}{2} & day 1 & 238 & 264 & 235 \\
\hline & & day 2 & 245 & 256 & 257 \\
\hline & & day 3 & 267 & 232 & 250 \\
\hline & \multirow{3}{*}{$\widetilde{\oplus}$} & day 1 & 235 & 213 & 201 \\
\hline & & day 2 & 202 & 203 & 239 \\
\hline & & day 3 & 238 & 241 & 250 \\
\hline \multirow{12}{*}{$\begin{array}{l}0 \\
\frac{0}{0} \\
\frac{0}{0} \\
0 \\
\tilde{O}\end{array}$} & \multirow{3}{*}{ Z } & day 1 & 277 & 269 & 240 \\
\hline & & day 2 & 301 & 290 & 318 \\
\hline & & day 3 & 241 & 255 & 227 \\
\hline & \multirow{3}{*}{$\bar{n}$} & day 1 & 264 & 266 & 263 \\
\hline & & day 2 & 332 & 292 & 313 \\
\hline & & day 3 & 272 & 281 & 267 \\
\hline & \multirow{3}{*}{2} & day 1 & 245 & 236 & 243 \\
\hline & & day 2 & 291 & 234 & 257 \\
\hline & & day 3 & 244 & 262 & 258 \\
\hline & \multirow{3}{*}{$\tilde{\infty}$} & day 1 & 276 & 296 & 254 \\
\hline & & day 2 & 252 & 268 & 252 \\
\hline & & day 3 & 268 & 237 & 261 \\
\hline
\end{tabular}




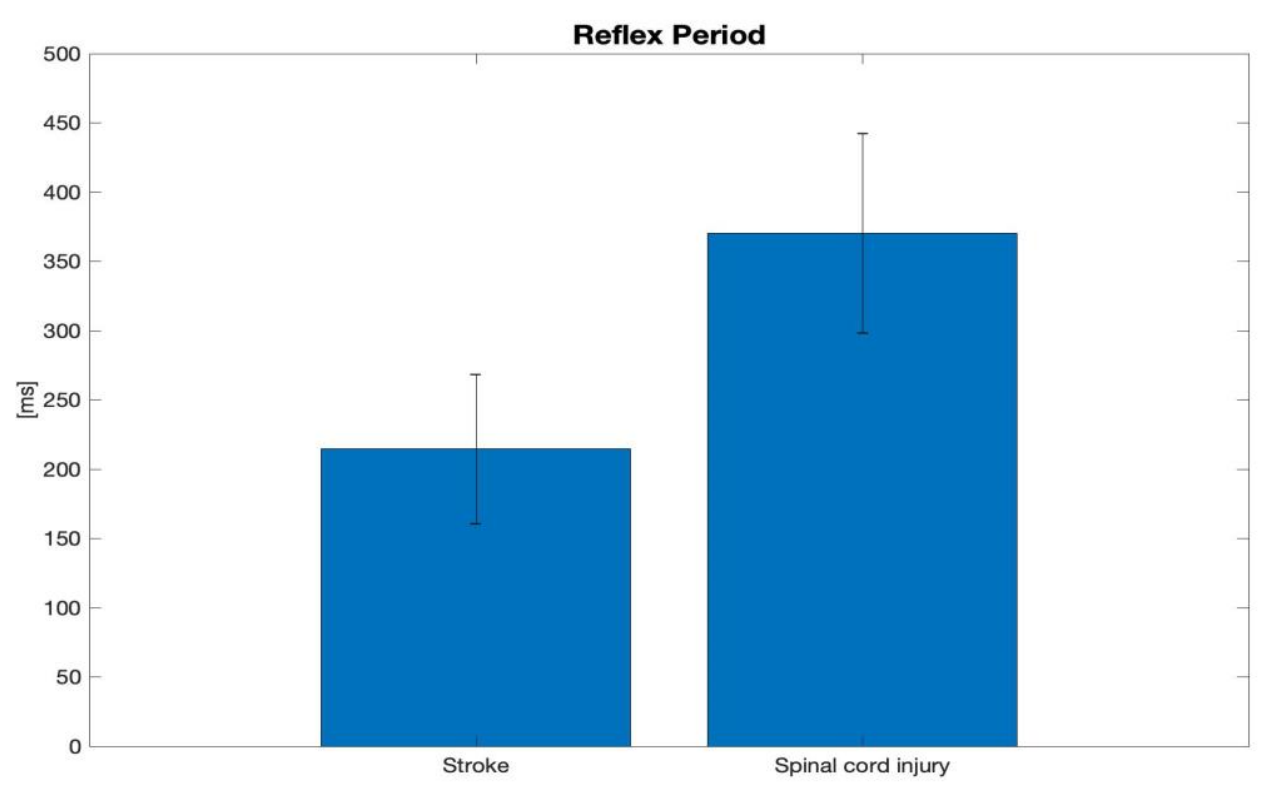

Fig 2. A comparison of the reflex period for stroke and spinal cord injury patients

the muscle spindle passes along to the spinal cord and synapses with the lower motor neuron that elicits a new impulse and initiates a muscle contraction. In patients suffering from spinal cord injury the damage is in the descending tracts that inhibit the lower motor neuron but in stroke patients the damage is in the brain. The difference in the RP of these two groups might therefore be explained by some excitatory mechanism originating in the brain. The main limitation of the present study is that the cohort of this research was relatively small considering that data from eight subjects in total was analyzed. More subjects and conditions have to be examined in order to establish a new parameter for spasticity measurement. In the presented work, a new method to quantify spasticity, the reflex period was exploited. RP is a parameter extracted from the Wartenberg test performed using goniometers along with electromyogram recordings of the quadriceps. The RP was defined as the time period from $50 \%$ of the maximum velocity of the leg to the first EMG signal indicating muscle contraction. This measurement method is promising because it combines both electrophysiological and biomechanical features.

\section{List of acronyms}

EMG - Electromyography

RP - Reflex Period

\section{Authors contributions}

TH played a main role in the conception and scope of the research project. $\mathrm{HKG}, \mathrm{BC}$ and the research group $\mathrm{TH}$, GM, GKL and VG conducted the assessment and data acquisition of spinal cord injury and stroke patients, respectively. $\mathrm{HKG}$ in the former patient group and $\mathrm{BC}$ in the latter. Data analyses were in the hands of KK and HK. Drafting and finalizing the proceeding was done by KK and $\mathrm{TH}$.

\section{Conflict of Interest}

The authors declare they have no conflicts of interest.

\section{Ethical Publication Statement}

We confirm that we have read the Journal's position on issues involved in ethical publication and affirm that this report is consistent with those guidelines.

\section{Corresponding Author}

Thordur Helgason, Health Technology Center,

Reykjavik University - Landspitali-University Hospital, 101 Reykjavik, Iceland.

ORCID iD: 0000-0002-5753-3217

Email: thordur@landspitali.is

\section{Email of co-authors}

Kristjana Kristinsdottir: kristjanak17@ru.is ORCID iD: 0000-0002-8821-8447

Gigja Magnusdottir: gigjamag@landspitali.is ORCID iD: 0000-0003-1848-1394

Belinda Chenery: belinda@styrkurehf.is

ORCID iD: 0000-0001-8052-6771

Vilborg Gudmundsdottir: vilbgu@lsh.is

ORCID iD: 0000-0002-4176-5785

Halla Kristin Gudfinnsdottir: halla@medor.is ORCID iD: 0000-0002-6055-6698

Halldor Karason: halldork15@ru.is ORCID iD: 0000-0003-1670-6676

Gudbjorg K Ludvigsdottir: gudbjl@landspitali.is ORCID iD: 0000-0001-7701-023X 


\section{High density EEG to assess TMS treatment in schizophrenia}

Eur J Transl Myol 30 (1): 154-159, 2020

\section{References}

1. Li S, Francisco GE. New insights into the pathophysiology of post-stroke spasticity. Front Hum Neurosci 2015;9:192. doi: 10.3389/fnhum. 2015.00192.

2. Lance JW. "Symposium synopsis" in Spasticity: Disordered motor control. Year Book Medical Publishers 1980;485:494.

3. Kuo CL, Hu GC. Post-stroke Spasticity: A Review of Epidemiology, Pathophysiology, and Treatments. International Journal of Gerontology 2018;12;280:4.

4. Burke D, Wissel J, Donnan GA. Pathophysiology of spasticity in stroke. Neurology 2013;15;80. doi: 10.1212/WNL.0b013e31827624a7

5. Booth CM, Cortina-Borja MJ, Theologis TN. Collagen accumulation in muscles of children with cerebral palsy and correlation with severity of spasticity. Dev Med Child Neurol 2001;43:314-20.

6. Romanini L, Villani C, Meloni C, Calvici V. Histological and Morphological aspects of Muscle in Infantile Cerebral Palsy. Ital J Orthop Traumatol 1989; 15:87-93.

7. Lieber RL, Steinman S, Barash IA, Chambers H. Structural and Functional Changes in Spastic Skeletal Muscle. MuscleNerve 2004;29:615-27.

8. Stecco A, Stecco C, Raghavan P. Peripheral Mechanisms Contributing to Spasticity and Implications for Treatment. Current Physical Medicine and Rehabilitation Reports 2014;2: 121-7.

9. Wartenberg R. Pendulousness of the Leg as a Diagnostic Test. Neurology 1951;1:18-24.
10. Fowler EG, Nwigwe AI, Wong Ho T. Sensitivity of the Pendulum Test for Assessing Spasticity in Persons with Cerebral Palsy. Dev Med Child Neurol 2000;42:182-9.

11. Syczewska M, Lebiedowska MK, Pandyan AD. Quantifying Repeatability of the Wartenberg Pendulum Test Parameters in Children with Spasticity. J Neurosci Methods 2009;178:340-4.

12. Whelan A, Sexton A, Jones M, et al. Predictive Value of the Pendulum Test for Assessing Knee Extensor Spasticity. Journal of NeuroEngineering and Rehabilitation 2018;15;68.

13. Bajd T, Vodovnik L. Pendulum Testing of Spasticity. Journal of Biomedical Engineering 1984;6:9-16.

14. White H, Uhl TL, Augsburger S, Tylkowski C. Reliability of the three-dimensional pendulum test for able-bodied children and children diagnosed with cerebral palsy. Gait and Posture 2007;26:97-105.

15. Bohannon RW, Harrison S, Kinsella-Shaw J. Reliability and Validity of Pendulum Test Measures of Spasticity obtained with the Polhemus Tracking System from Patients with Chronic Stroke. Journal of NeuroEngineering and Rehabilitation 2009;6;30.

16. Guðfinnsdóttir HK. Evaluation of tSCS treatment for the alleviation of lower limb spasticity. Master's Thesis at Reykjavík University, 2016.

Submitted: February 20, 2020

Revision received: March 9, 2020 Accepted for publications: March 11, 2020 